\title{
The Content, Intentionality, and Phenomenology of Experience Michelle Montague
}

\section{Introduction}

Intentionality can be simply characterized. It is nothing more or less than the phenomenon of something's being about something or of something (in the special sense of 'of' according to which a picture can be of something, such as a battle). Phenomenology can be characterized as there being something it is like experientially to be in a mental state, a state's having experiential qualitative character or subjective phenomenal character.

In contemporary analytic philosophy the attempt to 'naturalize' intentionality has dominated philosophical theorizing about this topic. The consensus was that the way to naturalize intentionality was to identify a natural relation that holds between states of the brain and states of the environment when and only when the former are about the latter. Philosophers pointed to the example of tree rings tracking the age of trees (an entirely non-mental phenomena) to ground the sense in which intentionality could be a natural relation. Internal states of the brain were thought to track the presence of specific external conditions in a fundamentally similar way, and to carry information about the environment in virtue of this tracking relation. Different theories expanded on this basic idea, diverging in their more detailed expositions of 'the tracking relation'.

Embedded in the 'naturalization' project was the assumption that there was a sharp theoretical distinction between intentional properties and phenomenological properties. This assumption can be characterized by a number of interconnected claims. First, it was assumed that there can be mental states such as beliefs and desires that have intentional properties but no phenomenological properties. Second, it was assumed that there can be mental states such as pain and after images that have phenomenological properties but no intentional properties. This presumed independence of intentional properties and phenomenological properties naturally led to the following claim:

(I) if a mental state $\mathrm{S}$ has both intentional properties and phenomenological properties, then they are logically independent of one another. 
Another notion that has been central to discussions of intentionality is that of 'content'. First, many philosophers take it that the claim

(2) all mental content is intentional content

is true by definition. For example, Crane (1995: p. 25) says, 'we may simply think of the content of a mental state as (somewhat vaguely) what the mental state is about.' Second, it was widely held that

(3) unconscious mental states-dispositional or not - can have any intentional content that conscious mental states can have.

It then seemed to naturally follow (and fully in accord with (I)) that

(4) a mental state S's property of having intentional content is not a phenomenological property of S and doesn't depend in any way on S's having any phenomenological properties.

Recently, philosophers have questioned claims (I) and (4), at least for the case of conscious perception. They have argued that in the case of conscious perception there is a (logically) intimate relationship between phenomenological properties and intentional properties or intentional content. Although I think claims (I) and (4) are false for conscious thought as well as conscious perception, in this paper I will only discuss perceptual experience. ${ }^{\mathrm{I}} \mathrm{I}$ will consider three theories - 'Standard representationalism', 'Fregeanism', and 'Brentanianism' - that all agree that there is an intimate relationship between phenomenology and intentionality, but disagree about the exact nature of this relationship. ${ }^{2}$

In discussing these theories I will focus on the notion of content, and argue that Brentanianism has the best account of the relationship between intentional properties and phenomenological properties. Although the truth of (2) is central to the Brentanian theory of content, unlike traditional theories I take it to be a substantive claim. Moreover, the explanation of its truth is central for showing the implausibility of Standard representationalism and

I See e.g. Horgan and Tienson 2002, Montague 20IO, and Strawson (201I) for discussions of the relationship between phenomenology and intentionality for conscious thought.

2 'Standard representationalism' should be sharply contrasted with what we might call 'Classical representationalism', the view proposed by John Lock that the immediate objects of perception are mind-dependent entities. 
Fregeanism. The plan of the paper is the following. In section 2 I introduce the basic framework of Brentanianism. In section 3 I briefly characterize Standard representationalism and Fregeanism. In section 4 I criticise these views in light of the Brentanian theory.

\section{Introduction to a Brentanian Theory of Content ${ }^{3}$}

I propose that our use of the notion of 'content' should allow us to speak of 'sensory content' (or, more widely, of phenomenological or experiential content such as pain) without commitment to (2). Now it may turn out that (2) is true, as I believe, that all mental content is intentional content-even sensory content that is thought to be the best example of non-intentional content. But if (2) is true, this should be a substantive claim rather than true by definition.

So, I begin with maximally inclusive conception of 'content'. According to this definition of content, the content, the total content, of an experience is absolutely everything that one experiences in having the experience. Equivalently,

(5) content is absolutely everything that is given to one, experientially, in the having of the experience. It is everything one is aware of in having the experience.

Given this broad definition of content, there will be many kinds of content included in any typical perceptual experience. This variety of content can usefully be divided into two kinds, phenomenological content and nonphenomenological content. To illustrate these kinds of content consider the experience of seeing a tree in leaf. So far as non-phenomenological content is concerned, I take it that the subject will be aware of at least the following: the tree itself; certain properties of the tree; spatial/positional information, i.e. information about how she is situated with respect to the tree; whatever innate or learned grasp of opportunities for action is essentially involved in her perceptual experience; temporal as opposed to spatial/positional information relevant for action. On the phenomenological side, the subject will be aware of the total phenomenological character of the experience, not only what one might think of as the 'merely sensory' what it's likeness of seeing

3 The Brentanian theory of content is so-called because it is loosely based on Franz Brentano's account of intentionality. 
colors and shapes, but also, and no less importantly, the what it's likeness of seeing something as a tree, and so on. All this will be part of the content of the perceptual experience.

Once this sense of 'phenomenological content' is introduced, we can ask again whether all content is intentional content. Some have wished to say no, holding that 'merely sensory' content (pain, for example) is not intentional at all. ${ }^{4}$ But this view may be questioned, even after we have allowed the legitimacy of the notion of 'merely sensory' content.

According to one venerable tradition, conscious intentional episodes, including both perceptual and emotional conscious episodes, are 'of', i.e. intentionally of, a whole lot more than just non-phenomenological content. The basic idea is simple and ancient - and Aristotelian. It is that in having a visual experience of a tree in leaf (for example), the subject, in addition to being aware of the tree and any other relevant external content, is also aware of the awareness of the tree. In having a particular conscious perceptual experience the subject is always and necessarily also aware of that very experience itself. There is always some sort of awareness of the experience or experiencing:

(6) conscious awareness always involves - constitutively involves - some sort of awareness of that very awareness. ${ }^{5}$

But - intentionality just is the property of aboutness or of-ness. So whatever an experience is about or of must be included in its intentional content. So an experience, considered just as such, or purely 'internalistically', is part of its own intentional content.

Most agree that my visual experience of a tree in leaf is about or of the tree and its shape and color, but many deny that it is also about or of its own visual phenomenological character. According to the view under discussion, however, there is a fundamental sense in which the visual (as opposed to say tactile) quality of one's seeing the tree is part of what one is aware of in having

4 See e.g. Block 2010.

5 This view is well expounded in the Phenomenological tradition. See e.g. Brentano, Husserl, Gurwitsch, etc. See also Kriegel 2009, Rosenthal 2005 and Zahavi 2006. Locke puts it strongly by saying that 'thinking consists in being conscious that one thinks' (I689: II.i. I9; he uses 'think' in the wide Cartesian to cover all conscious mental goings on). There are two main kinds of view that accept (6), 'higher order' views and 'same order' views. According to the former, a conscious state is conscious in virtue of a higher order state directed at it, and according to the latter, a conscious state's awareness of itself is part of that very state itself. As will become clear in section 4, the Brentanian theory argued for in this paper is an example of a 'same order' view. 
the experience. ${ }^{6}$ The greenness and shape of the tree is visually presented to me. And its being presented to me visually is part of the intentional content of the experience, on this view, because its being a visual experience is part of what I am aware of just in having it.

This awareness does not require the possession of the concept VISUAL EXPERIENCE, or BEING VISUAL. Rather, it follows immediately, from the fact that one's awareness of the world consists partly in one's being visually aware of the world, that one is, in having that experience, aware of the visual character of one's experience. And the content of this awareness of one's experience's being visual ${ }^{7}$ can be specified only in terms of (by reference to) the sensory phenomenology associated with visual experiences, i.e. what it's like to see colors, shapes, etc. So the phenomenological content essential to having an experience is part of an experience's intentional content, whatever else may be part of its intentional content. ${ }^{8}$

Claim (6) articulates the basic sense in which all of the phenomenological content of an experience is part of that experience's intentional content. In section 4, however, I will say in more detail how the intentionality and phenomenology of experience are related. This will involve two steps. First, I will articulate what the relationship is between the phenomenology of experience and the awareness of awareness feature of experience. Second, I will show how phenomenological properties are related to the properties we attribute to objects, focusing particularly on color experiences. With these two points outlined, I will go on to show what I take the shortcomings of Standard representationalism and Fregeanism to be. Before offering these criticisms, however, I will first briefly characterize these views in the next section.

6 Aristotle puts the point by saying that 'we perceive that we perceive', but the former kind of perceiving is obviously different from the latter: the claim is not that we see that we see. It is controversial what the first occurrence of perception amounts, and the present claim is simply that it will involve appeal to phenomenological properties, whatever its full account. See Caston 2002 for an excellent discussion.

7 Arguably there is more to an experience's being visual than sensory phenomenology, e.g. cognitive phenomenology. However, I will leave this issue aside for the purposes of this paper.

8 I should also note here the view, attributed to Husserl and Sartre and most recently defended by Zahavi 2006, which accepts that conscious awareness always involves awareness of awareness, but denies that this awareness of awareness should be understood in intentional terms. According to this view, awareness of awareness is an immediate, non-relational, noncognitive phenomenon. I'll put this debate to the side for the purposes of this paper. 


\section{Standard Representationalism and Fregeanism}

In this section I offer a brief explication of Standard representationalism and Fregeanism.

\subsection{Standard Representationalism}

What I am calling 'Standard representationalism' is the theory proposed by e.g. Dretske (I995), Harman (I990), and Tye (I995, 2000, 2002, 2009.) ${ }^{9}$ The basic claim is that the phenomenological character of experience is fixed by or identical to intentional content of a certain sort. If two experiences have the same intentional content (of a certain sort), then they have the same phenomenal character; if there is a difference in intentional content (of a certain sort), there will be a difference in phenomenal character.

The qualification 'of a certain sort' on 'intentional content' is a way for the representationalist to acknowledge the possibility that

[i] mental states such as dispositional beliefs may have intentional content but not possess any phenomenal character

and to claim that

[ii] contents may need to meet further conditions in order to be the phenomenal characters of experience. For example, Tye (I995) argues that in order for the content of a perceptual experience to be the phenomenal character of that experience that content must be poised to make the right sort of difference with respect to cognitive responses. Visual experiences, for example, must be apt for the production of beliefs, e.g. introspective beliefs about what is being experienced or beliefs about one's environment. In short, Tye argues that the phenomenal character of experience is one and the same as its poised abstract nonconceptual intentional content.

According to representationalism, then, experiences cannot vary in their phenomenal character while having the same intentional content, and expe-

9 There are many different versions of representationalism. For a discussion of these see e.g. Chalmers 2004. In this paper, I am only concerned with criticizing the version of representationalism advocated by Dretske, Harman and Tye. 
riences cannot vary in their intentional content while having the same phenomenal character. The following two conditionals, therefore, will be true:

[a] if two experiences have the same phenomenal character, then they will share (a kind of) intentional content; and

[b] if two experiences share (a kind of) intentional content, then they have the same phenomenal character.

The inverted earth thought experiment introduced by Block (I990) attempts to show [a] is false, and the inverted spectrum thought experiment attempts to show that $[\mathrm{b}]$ is false.

For my purposes here I accept the truth of [a] and will focus on it. I will call the kind of intentional content fixed by phenomenal character 'phenomenally fixed intentional content'. ${ }^{\text {Io }}$ Now the question is, what kind of intentional content is in question in [a]? As will become clear, the three theories under discussion have different conceptions of what the intentional content is that makes [a] true. To see what this intentional content is, at least in part, for the Standard representationalist, I will turn to one of the main considerations in favour of representationalism, the 'transparency thesis'.

According to the transparency thesis, when one considers one's experience in introspection one does not find properties of experience or any other perceptual intermediaries. All that one finds is that one is attributing properties to an object that the object appears to have. The intentional content of a perceptual experience is therefore only a matter of properties being attributed to objects. The way something appears is just a matter of the properties that thing appears to have. The position may be summed up as claiming that all there is to the intentional content of an experience are the properties we attribute to objects. Moreover, Standard representationalists also hold that the properties we attribute in having color experiences, for example, are physical properties, such as certain surface reflectance properties of objects. ${ }^{\text {II }}$

Chalmers 2004, 2006 and Thompson 2009 call this kind of content 'phenomenal content'. The qualification 'a kind of' on 'intentional content' is meant to leave open the possibility that phenomenologically identical experiences can diverge in the kinds of intentional content they possess. For example, according the Brentanian theory it is possible for two phenomenologically identical experiences to diverge in their non-phenomenological intentional content. See e.g. Siewert 1998, Horgan and Tienson 2002, and Siegel 2010 for a defense of the claim the idea that there is 'phenomenally fixed intentional content'. 


\subsection{Fregeanism}

In presenting the basic claim of the Fregean position as proposed by e.g. Chalmers (2004) and Thomson (2009). I will continue to focus on what I have called 'phenomenally fixed intentional content'. According to the Fregean view, if two subjects have phenomenally identical experiences, there is an important sense in which the way the world appears is the same. That is, the Fregean also accepts [a]: if two experiences have the same phenomenal character, the intentional content will be the same. But what does the Fregean mean by 'intentional content' in this context?

According to the Fregean, 'phenomenally fixed intentional content' is a matter of modes of presentations of properties and objects. Baldly stated, modes of presentation place a condition on reference, and so in virtue of this function can be thought of as being content. So with respect to phenomenally fixed intentional content, two phenomenally identical experiences have identical intentional content because of how the world is represented, and need not involve sameness of what is represented. For my purposes here, it will not be important whether modes of presentations are conceptual or non-conceptual. It is also an open question for this view whether there are other kinds of intentional content.

To get a bit clearer on the Fregean position consider Jack and Jill who have been inverts with respect to their red and green color experiences for their entire lives. Also assume that neither is a systematic misperceiver, what is sometimes called inverted spectra without illusion. When Jack views a lime and Jill views a strawberry they have phenomenally identical color experiences, let's call it 'phenomenally greenish experiences'. On the Fregean view, a 'phenomenally greenish experience' has a mode of presentation that picks out a property in the environment that typically causes phenomenally greenish experiences in the subject. (This mode of presentation may be said to place the following condition on reference: that which typically picks out a physical property in the environment that causes phenomenally greenish experiences in the subject.) $)^{12}$

Jack and Jill have the same mode of presentation but that mode of presentation picks out two distinct physical properties. Physical greenness typically causes green experiences in Jack and thus Jack's 'phenomenal greenish' mode of presentation refers to physical greenness. Physical redness typically causes

I2 There are a wide range of Fregean theories that may differ on their views about the particular nature of phenomenal modes of presentation. I have focused on Thompson's 2009 account for ease of exposition. 
green experiences in Jill and thus Jill's 'phenomenal greenish' mode of presentation refers to physical redness.

Both the Standard representationalist and the Fregean therefore agree that there is a logically intimate connection between the phenomenology of experience and the intentional content of experience. The Standard representationalist explains the connection in terms of property attributions made in experience. For example, the phenomenological 'bluish' character of my visual experience of seeing the blue ocean is accounted for in terms of my attributing the property blue to the ocean. What is essential for capturing the relationship between phenomenology and intentionality is what gets represented in experience. For the Fregean, the phenomenological 'bluish' character of my visual experience of seeing the blue ocean is accounted for in terms of a mode of presentation of e.g. physical blueness. What is essential for capturing the relationship between phenomenology and intentionality is how things get represented in experience.

In what follows I will argue that both views isolate something essential for capturing the relationship between the phenomenology and intentionality of experience, but both are phenomenologically inadequate. Contrary to Standard representationalism, we cannot explain the property attributions made in experience without appealing to how those property attributions are made, and this explanation itself requires appealing to phenomenology. And Fregeanism cannot simply appeal to modes of presentation, because it is a phenomenological datum that we do in fact make property attributions in experience, and these property attributions are intimately related to the phenomenology of experience.

\section{Objections to Standard Representationalism \& Fregeanism}

Standard representationalism and Fregeanism do not get the full picture of perceptual experience because neither view recognizes the awareness of awareness thesis and its role in explaining the relationship between the phenomenology and intentionality of experience.

Fregeanism is correct to focus on the fact that phenomenology is indispensible for explaining how we experience objects and properties in our environment, but flouts what is phenomenologically clear in claiming that it is not part of the phenomenology of experience that we attribute properties to objects. For example, Thompson (2009: p. II3) summarizes his view 
as follows: "The colour phenomenal properties that characterize a subject's perceptual experience are not, on this view, properties that the experience attributes to the external object of perception..." So, according to this view Thompson (2009: p. I09): "Fregean theories...do not entail that for any two phenomenally identical colour experiences there must be some properties that both experiences represent."

But this seems clearly false and false for phenomenological reasons. Given two phenomenally identical experiences that involve 'phenomenal redness', there is a sense in which they do attribute the same (or very similar) properties. (I'll explain the 'similarity' qualification below.) Chalmers (2006: p. 62) notes this objection to Fregeanism.

Intuitively, it seems to us that when we have an experience as of a colored object, there is a certain property (intuitively, a color property) that the object seems to have. And intuitively, it is natural to hold that the phenomenology of the experience alone suffices for it to seem that there is an object with that very property. That is, reflection on phenomenology suggests that there is an internal connection between phenomenology and certain properties that objects seem to have... a specific color experience seems to relate us to a specific color property.

Chalmers takes this phenomenological observation to push us in the direction of Standard representationalism. ${ }^{13}$ Since Standard representationalism holds that the color property we are related to in having a color experience is a physical property, a surface reflectance property, the internal connection between phenomenology and the properties of objects is an internal connection between phenomenology and surface reflectance properties. I don't think this picture gets the relata of the internal connection right. That is, the phenomenology of color experience is not internally connected to surface reflectance properties. Surface reflectance properties are not the right kinds of properties to be internally connected to phenomenology. My main reason for claiming this is that surface reflectance properties seem only causally and contingently related to 'phenomenological color properties', e.g. phenomenal redness, phenomenal blueness, etc. Rather than pursuing this objection in detail, however, what I hope to show is that with the awareness of awareness thesis, the Brentanian theory offers a more plausible account of the internal connection between phenomenology and the properties we attribute in experience.

To begin, it will be helpful to summarize briefly the awareness of aware- 
ness thesis. Part of what we are aware of when we see a physical object (and not just when we reflect on seeing a physical object) is the seeing itself, that is, the having of a visual experience. We are aware of the having of the visual experience in virtue of the phenomenological character of visual experience. So, in fact, in having visual experiences, we are aware of phenomenological properties, although in everyday activity, as Aristotle and Reid observed long ago, we are focused on the properties of objects, not on our particular perceptual access to them. These points can be summarized in the following claims.

[i] in general, in having an experience, one is aware of, one experiences, the experience as an experience ${ }^{14}$

SO

[ii] in having a visual experience, in particular, one experiences it as a visual experience - one is aware of it as a visual experience

[iii] being aware of an experience as a visual experience includes being aware of the phenomenology that is proprietary to visual experience, e.g. colour phenomenology, visual-shape phenomenology, etc.

The phenomenological features of experience are that in virtue of which an experience reveals itself as such, as the experience it is with the particular qualitative character that it has. The instantiation of a phenomenological property immediately reveals to one that one is having an experience, and so in having an experience one is immediately aware that one is having an experience. So, phenomenological properties reveal themselves as properties of experience. This, then, illustrates the first way in which Standard representationalism goes wrong. Phenomenological properties such as the "phenomenal redness' I experience in having a visual experience of a red round ball is experienced as a property of the experience itself. What is true is that it is not focally experienced as a property of experience.

I4 The sense in which one is aware of an experience as an experience should not be understood as involving the concept EXPERIENCE. I mean the phrase 'as an experience' in the same sense as Tye means experiencing a property as a property of an object in the following passage 2002: p. 448:"I found myself transfixed by the intense blue of the Pacific Ocean ... what I was focusing on, as it were, were a certain shade and intensity of the colour blue. I experienced blue as a property of the ocean not as a property of my experience." 
However, phenomenological properties do double duty: they not only reveal themselves in experience as essentially experiential, but they can also reveal (apparent) features of the world. I'll now turn to an explanation of how properties of experience, phenomenological properties, are related to the properties we attribute to objects, and the role awareness of awareness plays in explicating this relation.

What property do I attribute, in a naive ascription of colour? I attribute the property that I take to be revealed in the experience. But more than that ('revealed' can't do all the work, because someone might take the lightreflectance property of the object expressed in nanometres of wavelength to be 'revealed in' the experience): I attribute the property whose essential intrinsic character I take to be partly revealed in the qualitative character of the experience. So, contrary to Fregeanism, in the having of a visual experience as of a red round ball, for example, part of what is attributed to the object is a property essentially related to 'phenomenal redness', a property essentially related to redness as we experience it or redness as seen. Contrary to Standard representationalism, the property attributed to the object is internally linked to the phenomenological property we are aware of in having an experience. So, although I am happy to claim that phenomenological color properties track patterns of surface reflectance properties, surface reflectance properties are not internally linked to phenomenological properties.

Now the question arises as to how exactly the phenomenology makes a contribution to the property attribution in question? The basic idea can be summed up as follows:

[iv] it is partly in virtue of the subject's awareness of the sensory phenomenology of the visual experience that the phenomenology plays the role that it does in contributing to the experience's being about or focally directed towards the redness of the ball. It is partly because of one's awareness of experiencing 'phenomenal redness', for example, that one attributes a property that is essentially linked to 'phenomenal redness'.

In what way is the property attributed to the object 'essentially linked' to phenomenal redness? First, one is aware of the what it's likeness of experiencing red, or as we might say one is aware of the sensation of red or one is aware of 'phenomenal redness'. It is plausible that being aware of the sensation of red can be understood as being aware of a type in so far as one can experience the same sensation of red on many different occasions. However, in having 
the red, round ball experience, there is also a sense in which 'phenomenal redness' is experienced as a property of the object; there is a sense in which 'phenomenal redness' is attributed to the object. But the redness attributed to the object is experienced as an objective property of the object, not as a sensation, not as a property of experience. Nonetheless, there is clearly a relationship between the sensation of red one is aware of and the redness attributed to the object. This relationship cannot be a strict identity because as I have already mentioned, the sensation is experienced as a property of experience, whereas the redness attributed to the object is experienced as an objective property of the object. I propose that the relation is one of resemblance, and this resemblance relation should be understood as an intentional relation. An aspect of the redness sensation resembles an aspect of the redness attributed to the object, and it is in virtue of this resemblance that the experience attributes redness to the ball.

The resemblance could perhaps be more strongly understood as conveying the fact that we feel the experience of phenomenal redness gets it right about, it conveys part of the intrinsic qualitative character of, the objective property. Again, it can't be the case that it conveys the complete qualitative character of the objective property because of the fact that it is experienced as an objective property of the object. A question, therefore, for my account, that I do not have the space to address here, is how objective and subjective properties are experienced differently. I take it that experiencing a color property as objective will involve some appeal to spatial properties.

In summary, then, the awareness of awareness thesis, which is a way of saying what experience is, and giving the sense in which it is intentional with respect to its phenomenological properties, provides the background for explaining which property attributions are internally linked to phenomenology, e.g. the phenomenological properties we are aware of in having color experiences. The resemblance relation explains how the 'phenomenal property' gets linked to the property attributed to the object.

Of course there are well-known problems with explicating representation in terms of resemblance. The first thing to note is that I am not claiming that all representation is a matter of resemblance. I am only concerned with a certain class of properties that are experienced as part of conscious perception. In light of this, many of the problems with the resemblance theory of representation will not apply here. For example, I am not claiming that in order for the concept of a number to represent a number there must be some resemblance relation in place.

One problem that might be raised against my account is that resemblance is 
a symmetrical relation. ${ }^{15}$ So, for example, if a picture of Napoleon resembles Napoleon and so represents Napoleon in virtue of this resemblance, then because Napoleon resembles the picture does the man Napoleon also represent the picture of Napoleon? Clearly not. My general answer to this worry is that only mental states and experiences can be truly said to represent. So the reason we get representation in virtue of the resemblance relation for 'phenomenal redness' and the apparent property of the object that resembles 'phenomenal redness' is because 'phenomenal redness' is part of a conscious experience.

There is one important issue I have not dealt with in this paper, and can't adequately deal with here. That is, in attributing a color property to an object, exactly what kind of property gets attributed? I have claimed that 'phenomenal redness' is a property of experience, and thus a mind-dependent property. But what about the property that resembles 'phenomenal redness', the property that gets attributed to the object? Is it a mind-dependent property? If so, it may seem that my view is some version of projectivism, according to which, all of our color experiences are illusory. There may, however, be another option, in which color properties that get attributed are in a sense mind-dependent but nonetheless we are not required to say that all color experiences are illusions. I have in mind here something like P.F. Strawson's I979 attempt to reconcile our attributing 'phenomenal' color properties to objects and scientific realism, the idea that scientific knowledge is definitive of the nature of physical reality and makes no appeal to 'phenomenal' color properties.

The basic idea is that there is relativity of standards built into our attributions of particular visual properties, the broadest possible standard just being the perceptual point of view. Many ascriptions of visual properties absorb this relativity (a set of conditions which are taken to be normal or standard) without much notice. For example, we may say that the 'mountains are red-looking from a distance' but are 'blue-looking when climbing them'. Sometimes, however, we explicitly switch the standard. A piece of fabric magnified looks to be blue and yellow dots, but unmagnified looks to be green. Consider the two reports 'it's really blue and yellow dots', and 'it's really green'. Although these reports may appear inconsistent, if we consider that they are being made relative to different standards, we can see they are not. This case may be similar to seeing things from a distance. If a house looks blob-like from a distance, there is a sense in which the subject's experience 
isn't illusory. If we build a distance condition into the veridicality conditions of such an experience, the house looking blob-like is veridical. The property ascriptions made by scientific realism would simply be a more radical shift. The standards are set by the properties postulated by science. The radical shift involves a shift from a 'perceptual' point of view to an 'intellectual' point of view. Although I have only given a sketch of this proposal, I do think it provides one interesting way of avoiding the claim that our color experiences, for example, are inherently illusory.

In conclusion, I have argued that capturing the correct relationship between the intentionality and phenomenology of perceptual experience involves appealing to awareness of awareness, which is constitutive of conscious experience. Together with an appeal to the resemblance relation, I have explained the essential role phenomenology plays in explaining the property attributions made in perceptual experience. In so doing, I have tried to show how both Standard representationalism and Fregeanism fail to give an adequate account of perceptual experience.

\section{References}

Brentano, F.1874/1995. Psychology from an Empirical Standpoint. Introduction by P. Simons, translated by A.C. Rancurello, D.B. Terrell, and L. McAlister. London: Routledge.

Block, N. I990. Inverted Earth. In J. Tomberlin (ed), Philosophical Perspectives, 4: Action Theory and Philosophy of Mind.Atascadero, Calif.: Ridgeview: pp. 53-80.

-. 2010. Attention and Mental Paint. Philosophical Issues.

Crane, T. 1995. The Mechanical Mind. London and New York: Routledge.

Caston, V. 2002. Aristotle on Consciousness. Mind III: pp. 75I-8I8.

Chalmers, D. 2004. The Representational Character of Experience. In The Future of Philosophy, ed. B. Leiter. Oxford: Oxford University Press: pp. I53-8I.

- 2006. Perception and the Fall from Eden. In Perceptual Experience, eds. T. Gendler and J. Hawthorne. Oxford: Oxford University Press.

Dretske, F. 1995. Naturalizing the Mind. Cambridge, MA: MIT Press.

Harman, G. 1990. The Intrinsic Quality of Experience. Philosophical Perspectives, 4: pp. $3 \mathrm{I}-52$.

Horgan, T. and Tienson, J. 2002. The Intentionality of Phenomenology and the Phenomenology of Intentionality. In Philosophy of mind: classical and contemporary readings, ed. D. Chalmers. Oxford: OUP.

Husserl, E. 1900-1901/200I. Logical Investigations Vols I and 2. Translated by J. N. Findlay with revised translations by Dermot Moran. London and New York: Routledge.

Kriegel, U. 2007. Intentional Inexistence and Phenomenal Intentionality. Philosophical 
Perspectives $2 \mathrm{I}$.

- 2009. Subjective Consciousness. A Self-Representational Theory. Oxford and New York: Oxford University Press.

Levine, J. 2003. Experience and Representation. In Consciousness: New Essays, ed. Q. Smith and A. Jokic. Oxford: OUP.

Loar, B. 2003. Phenomenal Intentionality as the Basis of Mental Content. In Reflections and Replies: Essays on the Philosophy of Tyler Burge, eds. M. Hahn and B. Ramberg. MIT Press

Montague, M. 20Io. Recent Work on Intentionality. Analysis 70 (4): pp. 765-782.

Rosenthal, D. 2005. Consciousness and Mind. Oxford: Oxford University Press.

Siegel. S. 20io. The Contents of Visual Experience. New York: Oxford University Press.

Siewert, C. I998. The Significance of Consciousness. Princeton: Princeton University Press.

Strawson, G. 20ıı. Cognitive Phenomenology: Real Life. In Bayne and Montague (eds) Cognitive Phenomenology. Oxford: Oxford University Press.

Strawson, P.F. I979/201 . Perception and its Objects. In his Philosophical Writings. Oxford: Oxford University Press.

Thompson, B. 2009. Senses for Senses. Australian Journal of Philosophy, Vol 87 No I: pp. 99-II7.

Tye, M. I995. Ten Problems of Consciousness. Cambridge, MA: MIT Press.

-. 2000. Consciousness, Color, and Content. Cambridge, MA: MIT Press.

- 2002.Visual Qualia andVisual Content Revisited. In Philosophy of Mind: Contemporary and Classical Readings, ed. D. Chalmers. Oxford: Oxford University Press.

- 2009. Representationalist Theories of Consciousness. In The Oxford Handbook of Philosophy of Mind, eds B. McLaughlin, A Beckerman and S. Walter. Oxford: Oxford University Press.

Zahavi, D. 2006. Subjectivity and Selfhood: Investigating the first-person perspective. Cambridge, MA: MIT Press. 